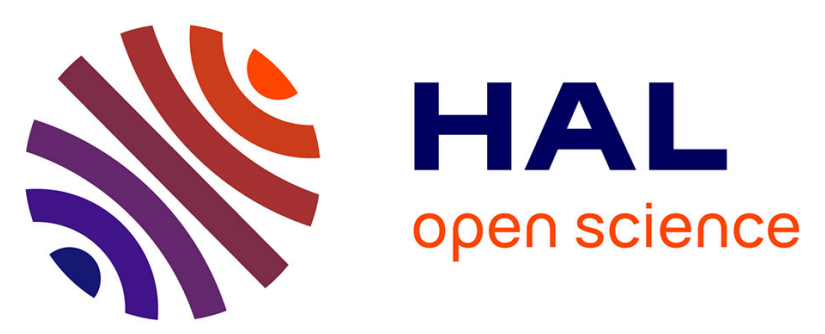

\title{
Impact of the acoustic forcing level on the transfer matrix of a turbulent swirling combustor with and without flame
}

R Gaudron, Marco Gatti, Clement Mirat, Thierry Schuller

\section{To cite this version:}

R Gaudron, Marco Gatti, Clement Mirat, Thierry Schuller. Impact of the acoustic forcing level on the transfer matrix of a turbulent swirling combustor with and without flame. Flow, Turbulence and Combustion, 2019, 103 (3), pp.751-771. 10.1007/s10494-019-00033-z . hal-02512043

\section{HAL Id: hal-02512043 \\ https://hal.science/hal-02512043}

Submitted on 19 Mar 2020

HAL is a multi-disciplinary open access archive for the deposit and dissemination of scientific research documents, whether they are published or not. The documents may come from teaching and research institutions in France or abroad, or from public or private research centers.
L'archive ouverte pluridisciplinaire HAL, est destinée au dépôt et à la diffusion de documents scientifiques de niveau recherche, publiés ou non, émanant des établissements d'enseignement et de recherche français ou étrangers, des laboratoires publics ou privés. 


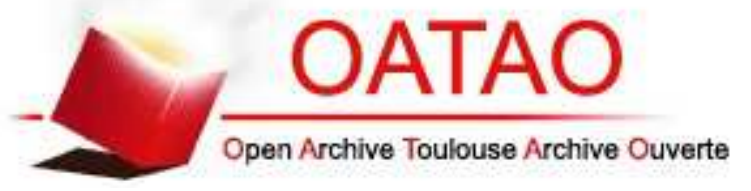

\section{Open Archive Toulouse Archive Ouverte}

OATAO is an open access repository that collects the work of Toulouse researchers and makes it freely available over the web where possible

This is an author's version published in: https://oatao.univ-toulouse.fr/25709

\section{Official URL:}

https://doi.org/10.1007/s10494-019-00033-z

\section{To cite this version:}

Gaudron, Renaud and Gatti, Marco and Mirat, Clément and Schuller, Thierry Impact of the acoustic forcing level on the transfer matrix of a turbulent swirling combustor with and without flame. (2019) Flow, Turbulence and Combustion, 103 (3). 751-771. ISSN 1386-6184

Any correspondence concerning this service should be sent to the repository administrator: tech-oatao@listes-diff.inp-toulouse.fr 


\title{
Impact of the Acoustic Forcing Level on the Transfer Matrix of a Turbulent Swirling Combustor with and Without Flame
}

\author{
R. Gaudron ${ }^{1}$ (D) $\cdot$ M. Gatti ${ }^{1}$. C. Mirat ${ }^{1} \cdot$ T. Schuller $^{1,2}$
}

\begin{abstract}
Thermoacoustic instabilities are a major issue for industrial and domestic burners. One possible framework to study these instabilities is to represent the system by a network of Dimensionless Acoustic Transfer Matrices (DATM) that link pressure and velocity fluctuations upstream and downstream each element of the network. In this article, the DATM coefficients of a turbulent swirling combustor are determined for a thermoacoustically stable configuration using harmonic acoustic forcing. Since the dynamics of the whole system is controlled by nonlinearities, the impact of the forcing level needs to be considered. The four DATM coefficients are thus measured for reactive operating conditions (premixed flame) and cold flow conditions for increasing acoustic excitation levels. The velocity level is controlled by a hot wire located inside the injector, in a region with a laminar top-hat velocity profile. The upstream and downstream specific acoustic impedances are also measured. Results for the acoustic response under cold flow conditions are first presented. In this case, the DATM coefficients are found to be independent of the forcing level except for the modulus of the coefficients linking the downstream velocity fluctuations to the upstream pressure and velocity fluctuations. This behavior is linked to the nonlinear response of the injector but is not entirely captured by the acoustic network model developed in this work. For reactive operating conditions, measurements indicate that all DATM coefficients depend on the forcing level to a certain extent. The Flame Describing Function, linking heat release rate fluctuations to velocity fluctuations, is used to reconstruct the transfer matrix through an acoustic network model. This network model accurately predicts the trend of the measured coefficients but the impact of the forcing level is not reproduced. Saturation for reactive operating conditions is shown to be not only related to the nonlinear flame response but also to the nonlinear injector dynamics. Finally, a data-driven reconstruction of the FDF using the acoustic network model along with the hot wire and microphone measurements is performed. This data-driven acoustic reconstruction is subsequently compared with the FDF determined with an optical technique.
\end{abstract}

R. Gaudron

renaud.gaudron@centraliens.net 
Keywords Thermoacoustic instabilities - Dimensionless Acoustic Transfer Matrix · Acoustic network model · Flame Describing Function · Nonlinear flame dynamics · Acoustic damping

\section{Introduction}

The combination of the Flame Transfer Function (FTF) or its nonlinear extension, the Flame Describing Function (FDF), with an acoustic solver has been shown to be a powerful framework to analyze the thermoacoustic stability of practical combustors at reduced computational costs [1-5]. In these low-order representations, the frequency response of the flame to sound waves is encompassed in the complex function called FTF and defined as [6]:

$$
F(\omega)=\frac{\dot{Q}^{\prime} / \overline{\dot{Q}}}{u^{\prime} / \bar{u}}
$$

where $\dot{Q}$ denotes the flame heat release rate and $u$ the flow velocity at some location inside the injector. Throughout this work, the overline stands for mean conditions and the prime corresponds to the Fourier component of the signal at the forcing angular frequency $\omega$. When the forcing level $\left|u^{\prime}\right| / \bar{u}$ is an explicit variable of $F$, the operator defined in Eq. 1 becomes nonlinear and is called a Flame Describing Function (FDF) [7, 8]. This framework can be used to analyze the dynamics of each mode of the combustor and determine the oscillation frequency and oscillation level reached by the acoustic variables within the system. This procedure was successfully employed to predict the thermoacoustic stability of turbulent swirling combustors $[9,10]$. One challenge is to accurately determine the FDF, i.e. the frequency response of the flame when submitted to flow perturbations, over the frequency range of interest and at high perturbation amplitudes [11, 12].

There are a few analytical expressions for the FTF of canonical flames that were derived with simplifying assumptions [13, 14]. Alternatively, the FTF can be determined using numerical means $[15,16]$. However, simulations of the frequency response of practical swirling flames in industrial combustors are often limited to a single or a limited set of forcing frequencies due to the large computational resources needed for these calculations and the forcing level is rarely varied [17]. There is a growing effort to reproduce the FDF over the entire frequency range of interest and for multiple perturbation amplitudes $[15,18,19]$. Han et al. [18] carried out simulations of the FDF of a premixed swirling flame in a lab scale burner over a wide range of forcing frequencies and forcing levels. These data were then used to determine the combustor stability and the trajectories of the unstable modes when submitted to perturbations of increasing amplitudes [16]. However, simulations reproducing the FDF remain exceptions and large deviations are still observed between the simulated flame frequency responses and measurements [18]. In many nonlinear stability analyses, the FDF is then modeled by a heuristic expression $[20,21]$ or determined by dedicated experimental means [8-10,22].

On the experimental side, large actuators are needed in order to perturb the flow and reach high forcing levels [23]. Another difficulty is to determine the heat release rate. In fully premixed systems, it is common to rely on the proportionality of the chemiluminescence intensity and the combustion intensity [24]. The FTF and FDF can then be determined by an optical setup recording the light emission from selected intermediate combustion radicals, such as $\mathrm{OH}^{*}$ or $\mathrm{CH}^{*}$, which concentrations are assumed to be proportional to the rate of 
heat released by the flame [24]. This method requires an optical access that covers the full combustion region and as a consequence is often limited to the determination of FTF/FDF in lab scale setups.

In non fully-premixed systems, where it is more difficult to measure the flame heat release rate, or in combustors operating at higher powers with limited access to the flame region, a purely acoustic method is preferred [25-28]. In this case, the flame response to sound waves can be represented by a $2 \times 2$ Dimensionless Acoustic Transfer Matrix (DATM) denoted by $\widetilde{M}$ in this work and linking the acoustic variables upstream and downstream the flame:

$$
\left(\begin{array}{c}
p_{d}^{\prime} / z_{d} \\
u_{d}^{\prime}
\end{array}\right)=\left(\begin{array}{cc}
\widetilde{M}(1,1) & \widetilde{M}(1,2) \\
\widetilde{M}(2,1) & \widetilde{M}(2,2)
\end{array}\right) \times\left(\begin{array}{c}
p_{u}^{\prime} / z_{u} \\
u_{u}^{\prime}
\end{array}\right)
$$

where the subscripts $u$ and $d$ denote upstream and downstream variables respectively. In order to obtain dimensionless coefficients, the downstream $p_{d}^{\prime}$ and upstream $p_{u}^{\prime}$ acoustic pressures are divided by their respective characteristic impedances, $z_{d}$ and $z_{u}$. The upstream and downstream locations should be as close to the flame as possible [29]. This approach was originally developed for non-reactive 1D duct networks [30, 31] but was then extended to networks containing a reactive element [1]. For a compact flame stabilized in a low-Mach number flow within a straight duct, one may easily link the DATM describing the acoustic response of the flame and the FTF:

$$
\tilde{M}=\left(\begin{array}{cc}
z_{u} / z_{d} & 0 \\
0 & 1+F\left(\bar{T}_{d} / \bar{T}_{u}-1\right)
\end{array}\right)
$$

where $T$ is the gas temperature. In many test rigs, the acoustic states upstream $\left(p_{u}^{\prime}, u_{u}^{\prime}\right)$ and downstream $\left(p_{d}^{\prime}, u_{d}^{\prime}\right)$ the flame cannot be determined close enough to the combustion region. Moreover, they need to be determined in regions of the flow were the waves are planar and in the absence of acoustic sources [31]. These conditions are generally achieved with a series of wall microphone measurements in straight ducts upstream the injector and downstream the combustion chamber $[26,27]$. The drawback is that the distance between the upstream and downstream measurement locations is no longer compact with respect to the wavelengths of sound waves and an acoustic network model needs to be considered to reconstruct the acoustic states just upstream and downstream the flame. This acoustic network model consists in several DATM describing the acoustic response of various elements of the burner such as straight tubes, sudden area changes or sudden pressure drops [27, 29].

Measuring the DATM describing the acoustic response of practical burners is now well mastered [25, 32]. One of the first measurements of the modulus and phase of the four DATM coefficients for cold and reactive operating conditions [26] was achieved using a two-source method [30, 31] by forcing the burner from the upstream and downstream sides with harmonic sound waves. Due to the high level of noise produced by the turbulent flow inside the burner, a large number of forcing cycles needs to be recorded to extract the coherent response of the system. Further efforts were put into modeling and measuring the DATM coefficients of a swirling combustor for cold flow operating conditions [27]. A summary of the DATM modeling and measurement techniques can be found in [28], where the agreement between theory and experiments is good, even for reactive operating conditions.

The DATM corresponding to the flame response can also be reconstructed using numerical simulations. Different strategies were developed and compared to analytical expressions or experiments with satisfactory agreement [33-37]. However, the forcing level is never considered in these experimental or numerical reconstructions of the flame DATM or is kept 
constant at an arbitrary small value. A consequence of this representation is that the flame response is assumed to be independent of the forcing amplitude $\left|u_{0}^{\prime}\right| / \bar{u}_{0}$, an approximation which only holds for small acoustic levels [7, 13, 38, 39]. For sizable forcing levels, an equivalent to the FDF has to be defined for the flame DATM.

The aim of this study is to determine the four DATM coefficients of a fully premixed turbulent swirling combustor between $f=20 \mathrm{~Hz}$ and $400 \mathrm{~Hz}$ for cold and reactive operating conditions and for increasing forcing levels $\left|u_{0}^{\prime}\right| / \bar{u}_{0}$ measured with a hot wire probe located inside the injector. For cold flow operating conditions, experiments are carried out for forcing levels ranging from $\left|u_{0}^{\prime}\right| / \bar{u}_{0}=0.10$ to 0.72 RMS. For reactive operating conditions, the same experiments are repeated for four forcing levels $\left|u_{0}^{\prime}\right| / \bar{u}_{0}=0.10,0.20,0.30$ and 0.55 RMS. Measurements for the DATM representing the acoustic response of the combustor are then analyzed and compared to a reconstruction for cold and reactive operating conditions. In this second case, the reconstruction is based on the FDF, which is measured in a separate set of experiments with an optical technique.

A description of the experimental setup and of the measurement techniques is presented in Section 2. The acoustic network model describing the acoustic response of the combustor for cold and reactive operating conditions is described in Section 3. Measurements and reconstructions of the DATM coefficients for cold and reactive operating conditions are finally discussed in Section 4.

\section{Experimental Setup}

The setup represented in Fig. 1 is used in the present study. A mixture of methane and air is injected in a tranquilization box by two opposed apertures. A loudspeaker (Monacor SP6/108PRO - $100 \mathrm{~W}$ RMS) is sealed at the bottom of the tranquilization box and used to generate harmonic sound waves. The flow is then pushed through an anti-flashback grid and a honeycomb structure that breaks the large turbulence scales. A plenum followed by a convergent nozzle (contraction ratio: 8.73) generates a fully laminar flow with a top-hat velocity profile. A hot wire probe denoted by HW in Fig. 1 (Dantec Dynamics Mini-CTA $54 \mathrm{~T} 30$ with a $55 \mathrm{P} 16$ probe) measures the velocity signal $\bar{u}_{0}+u_{0}^{\prime}$ in the top-hat region of the flow. At the same axial location, a microphone denoted by MHW in Fig. 1 (Bruel \& Kjaer 4938) linked to a conditioning amplifier (Bruel \& Kjaer 2690) measures the acoustic pressure $p_{u}^{\prime}$. A swirler featuring 6 holes of radius $R=3 \mathrm{~mm}$ generates a flow with a swirl number $S=0.8$ that was measured using Laser Doppler Velocimetry at the burner outlet. A cooling support is used to prescribe the temperature of the combustion chamber backplate. A bluff body of conical shape is used to promote flame stabilization. Optical access in the combustion chamber is granted by four quartz windows that are transparent for both the visible and the near ultraviolet wavelengths. A water-cooled convergent nozzle (contraction ratio: 2.03) is added at the top of the combustion chamber, followed by an exhaust tube of variable length.

Three microphones (Bruel \& Kjaer 4938) denoted by ME, ME' and ME" in Fig. 1 are mounted on water-cooled waveguides. The small acoustic distortions induced by these waveguides are corrected through the use of their transfer function, determined in a separate set of experiments. The first two microphones, ME and ME', are located in front of each other in the exhaust tube. A third microphone, ME", is located $50 \mathrm{~mm}$ downstream. The 


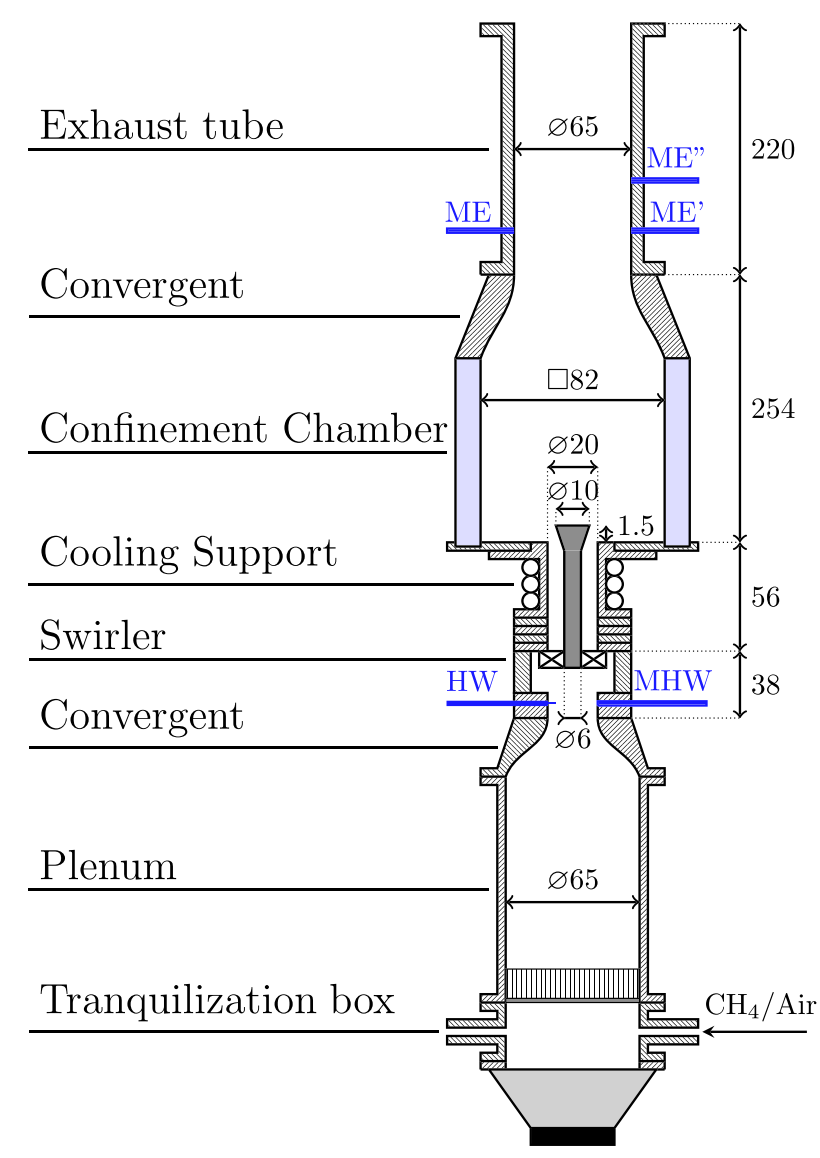

Fig. 1 Experimental setup used to determine the Dimensionless Acoustic Transfer Matrix (DATM) and the Flame Describing Function (FDF) for cold and reactive operating conditions. The exhaust tube of length $L=220 \mathrm{~mm}$ is used as the first load. All dimensions are in millimeters

Three-Microphone Method [40] is used to reconstruct the acoustic velocity fluctuations $u_{d}^{\prime}$ at the same axial position as the acoustic pressure $p_{d}^{\prime}$ measured by ME'. In order to increase the accuracy of the Three-Microphone Method, all experiments are made twice: one with the microphones set in their original configuration, as represented in Fig. 1, and another one with the microphones ME' and ME"' switched [40, 41]. Coherence functions are also used to further improve the signal-to-noise ratio [40]. All pressure signals are divided by their associated characteristic impedance $\bar{\rho} \bar{c}$ where $\bar{\rho}$ is the mean gas density and $\bar{c}$ the mean speed of sound, both of which are determined at the microphone location.

The Dimensionless Acoustic Transfer Matrix (DATM) links the downstream acoustic fluctuations to the upstream acoustic fluctuations as expressed in Eq. 2. This expression contains four unknown coefficients $\widetilde{M}(1,1), \widetilde{M}(1,2), \widetilde{M}(2,1), \widetilde{M}(2,2)$ for only two equations. As a consequence, two independent acoustic states are needed in order to determine 
these coefficients. In many experiments, the two-source method is used [25-28]. An equivalent method called the two-load method [42] is used here. Both methods are based on a modification of at least one acoustic boundary condition of the setup. The first load for both cold and reactive operating conditions corresponds to the configuration shown in Fig. 1 with an exhaust tube of length $L=220 \mathrm{~mm}$. The second load for cold flow operating conditions is obtained with a longer exhaust tube of length $L=440 \mathrm{~mm}$, i.e. twice as large as the first one. This latter configuration is thermoacoustically unstable in the reactive case. Another load consisting of an exhaust tube of length $L=220 \mathrm{~mm}$ topped by a perforated plate featuring a square pattern of 12 holes of radius $R_{*}=2.5 \mathrm{~mm}$ with an inter-hole space $d_{*}=20 \mathrm{~mm}$ is thus employed as the second load for reactive operating conditions. It was checked for cold and reactive operating conditions that these two configurations lead to independent acoustic states for all frequencies of interest.

A photomultiplier (Hamamatsu H5784-04) equipped with a band-pass filter (Asahi Spectra ZBPA310, centered on $\lambda=310 \mathrm{~nm}$ and with a $10 \mathrm{~nm}$ bandwidth) records the $\mathrm{OH}^{*}$ chemiluminescence signal. This signal is assumed to be linearly related to the heat release rate [24]. The Flame Describing Function (FDF) is deduced from the cross correlation between the photomultiplier signal and the hot wire (HW) signal divided by the auto correlation of the hot wire signal. All time series contain at least 40 oscillation cycles.

An ICCD camera (Princeton Instruments PI-MAX 4) equipped with the same interferometric filter (Asahi Spectra ZBPA310) is used to record flame images with a long exposure time in the absence of external forcing, as represented in Fig. 2.

The reactive configuration investigated in this study is a perfectly premixed methane/air flame with an equivalence ratio $\phi=0.82$ and a thermal power of $5.5 \mathrm{~kW}$. The associated bulk velocity at the hot wire location is $\bar{u}_{b}=5.4 \mathrm{~m} / \mathrm{s}$ in a tube of diameter $D=22 \mathrm{~mm}$ for a mixture at the ambient temperature $\bar{T}=293$ K. For cold flow operating conditions, methane is not injected and the air mass flow rate is adjusted in order to reach the same bulk velocity $\bar{u}_{b}$ as for reactive operating conditions. For both cold and reactive operating conditions, the highest velocity reached by the mean flow is $\bar{u}_{\max }=12 \mathrm{~m} / \mathrm{s}$ inside the swirler injection holes. It corresponds to a Mach number $M=0.035$ meaning that the flow remains incompressible everywhere inside the setup.

Fig. 2 Mean $\mathrm{OH}^{*}$ light emission distribution for steady flow injection conditions. $\phi=0.82$, $\bar{u}_{b}=5.4 \mathrm{~m} / \mathrm{s}$

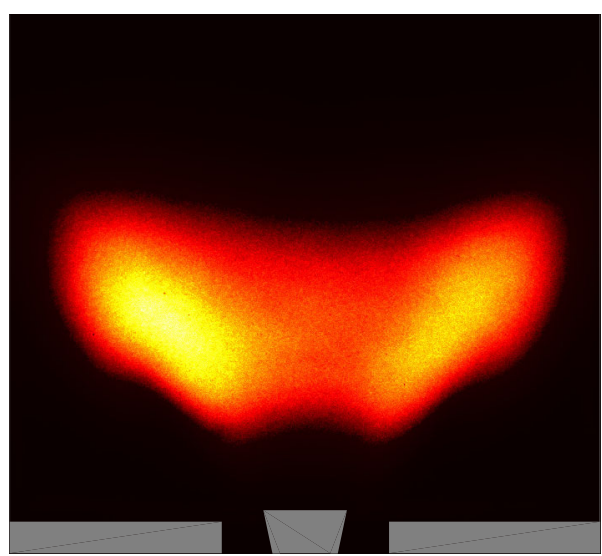




\section{Acoustic Network Models}

The acoustic response of the experimental setup is now modeled for cold and reactive operating conditions using the acoustic two-port matrices network formalism [2, 25, 27, 30, $33,43]$. The harmonic convention retained here is $\exp (+i \omega t)$ and all pressure signals are divided by the characteristic impedance $z=\bar{\rho} c$ in order to obtain DATM coefficients, as expressed in Eq. 2. Since the procedure presented in the previous section leads to DATM measurements covering the region between the hot wire probe HW location and the downstream microphone ME" location, the analysis presented here focuses on these central elements only.

The central elements of the experimental setup, sketched in Fig. 3-(Left), are modeled by a network of two-port matrices representing their acoustic response between the hot wire HW location defined as section (0) in Fig. 3-(Right) and the microphone ME" location defined as section (11) in Fig. 3-(Right). The injector is comprised between section (0) and section (8) and includes the swirling vane and the injection tube. It is followed by the combustion chamber between section (8) and section (9) and the downstream elements between section (9) and section (11). The swirling vane is represented by the elements comprised between section (3) and section (6). For reactive operating conditions, the flame

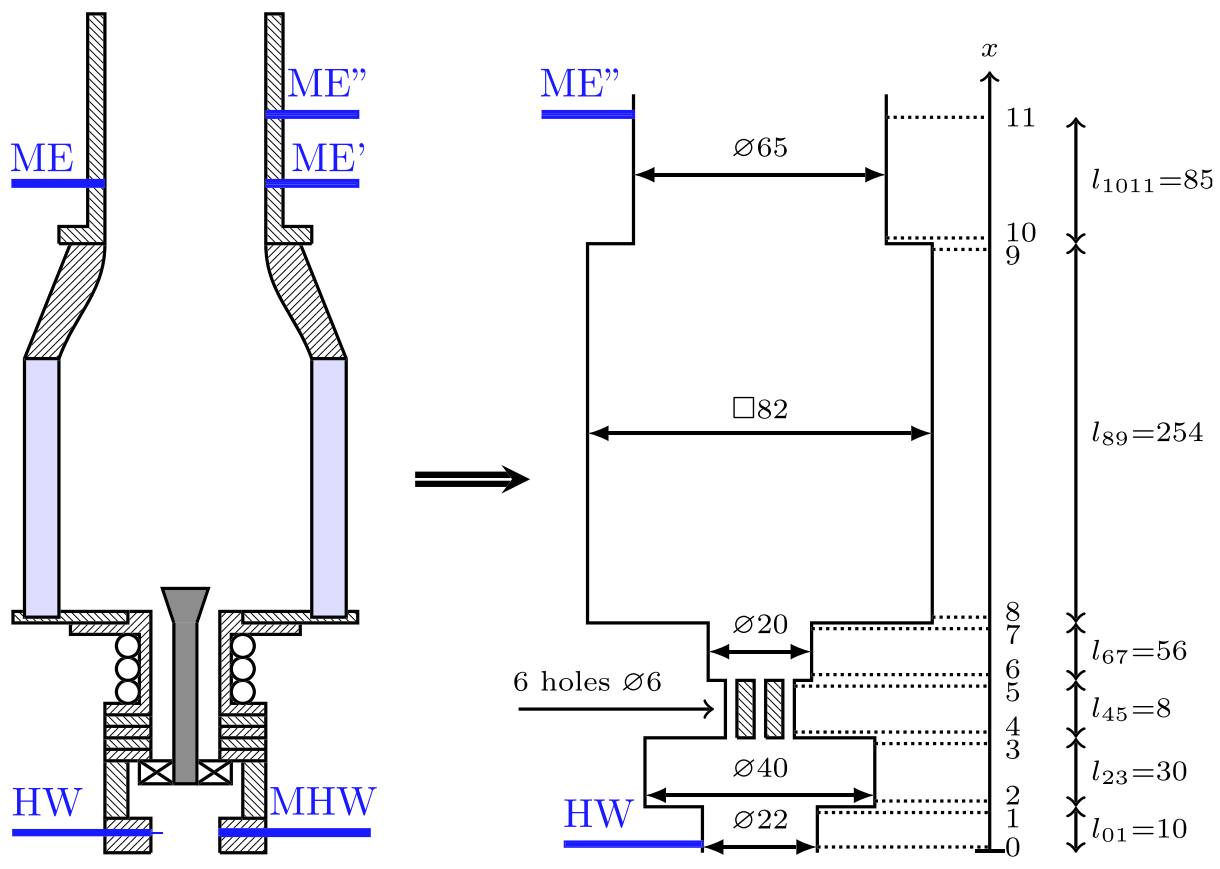

Fig. 3 (Left) Central elements of the experimental setup used to determine the DATM coefficients for cold and reactive operating conditions. The hot wire probe HW and facing microphone MHW are used to determine the acoustic velocity $u_{0}^{\prime}$ and acoustic pressure $p_{0}^{\prime}$ in section (0). The downstream microphones ME, ME' and ME" are used to determine the acoustic velocity $u_{11}^{\prime}$ (using the Three-Microphone Method) and acoustic pressure $p_{11}^{\prime}$ in section (11). (Right) Acoustic network model representing the injector and burner dynamics for cold and reactive operating conditions. All dimensions are in millimeters 
is assumed to be stabilized at the axial location corresponding to section (8) and is treated as a compact element.

The acoustic response of these elements are modeled using a limited number of analytical DATM corresponding to simple canonical cases. This first canonical expression corresponds to the DATM of a straight duct in a uniform low-Mach non-reactive flow, given by:

$$
\tilde{M}_{d u c t}=\left(\begin{array}{cc}
\cos (k l) & -i \sin (k l) \\
-i \sin (k l) & \cos (k l)
\end{array}\right)
$$

where $k=\omega / c$ is the wave number and $l$ is the length of the straight duct.

The second expression corresponds to the DATM of a compact area change in a lowMach non-reactive flow, given by:

$$
\tilde{M}_{\text {area }}=\left(\begin{array}{cc}
1 & 0 \\
0 & A_{u} / A_{d}
\end{array}\right)
$$

where $A_{u}$ and $A_{d}$ are the cross section areas upstream and downstream the area change respectively.

Finally, the acoustic damping generated across the swirler is expected to be sizable and thus should be accounted for in order to accurately predict the acoustic response of the injector [44]. Several DATM models for the swirling vane with and without acoustic damping are tested against experimental measurements in the next section, including a compact area change, modeled by Eq. 5 and linear and nonlinear extensions of Howe's model [44, $45,50]$. In the end, it is shown that the swirler is best modeled as a compact perforated plate sustaining a high-Reynolds flow. The corresponding nonlinear DATM model is given by:

$$
\tilde{M}_{\text {swirl }}=\left(\begin{array}{cc}
1 & -i k A_{u} /\left(N K_{r}\right) \\
0 & A_{u} / A_{d}
\end{array}\right)
$$

where $K_{r}$ is the Rayleigh conductivity of the swirler based on a nonlinear extension of Howe's model $[45,46]$, and $N=6$ is the number of perforations across the swirler. The swirler finite thickness as well as the nonlinear acoustic damping are considered in this model [44, 47-50].

Equations 4-6 are then utilized to describe the acoustic response of the elements represented in Fig. 3-(Right) while Eq. 3 is used to describe the flame response to sound waves. The subsequent acoustic network model is represented for cold and reactive operating conditions in Fig. 4 where each black box describes an acoustic element located between section (i) and section (j) using a DATM denoted by $\widetilde{M}_{i j}$. The blue color indicates elements filled with fresh gases while the red color indicates those filled with burnt gases of average temperature $\bar{T}_{b}=1200 \mathrm{~K}$.

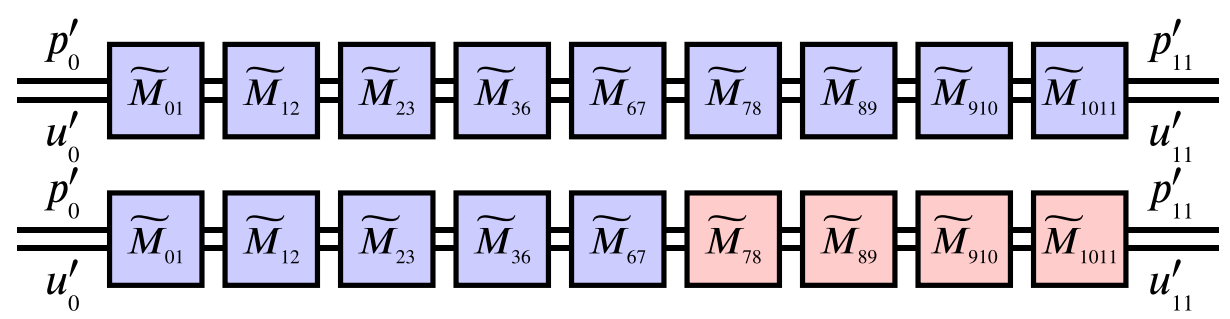

Fig. 4 Acoustic network models representing the Dimensionless Acoustic Transfer Matrix of the experimental setup between section (0) and section (11) for cold flow operating conditions (Top) and reactive operating conditions (Bottom). Blue elements are filled with fresh gases while red elements are filled with burnt gases 
The DATM model given by Eq. 4 and corresponding to a straight duct is used for $\tilde{M}_{01}$, $\widetilde{M}_{23}, \widetilde{M}_{67}, \widetilde{M}_{89}$ and $\widetilde{M}_{1011}$. The DATM model given by Eq. 5 and corresponding to a sudden area change is used for $\widetilde{M}_{12}$ and $\widetilde{M}_{910}$. The nonlinear DATM model given by Eq. 6 and corresponding to a compact perforated plate sustaining a high-Reynolds flow is used for $\widetilde{M}_{36}$. Finally, the DATM model employed for $\widetilde{M}_{78}$ differs for cold and reactive operating conditions: for cold conditions, a simple area change model, given by Eq. 5 is used. For reactive conditions, the previous DATM model is combined with the DATM model describing the flame acoustic response, given by Eq. 3 .
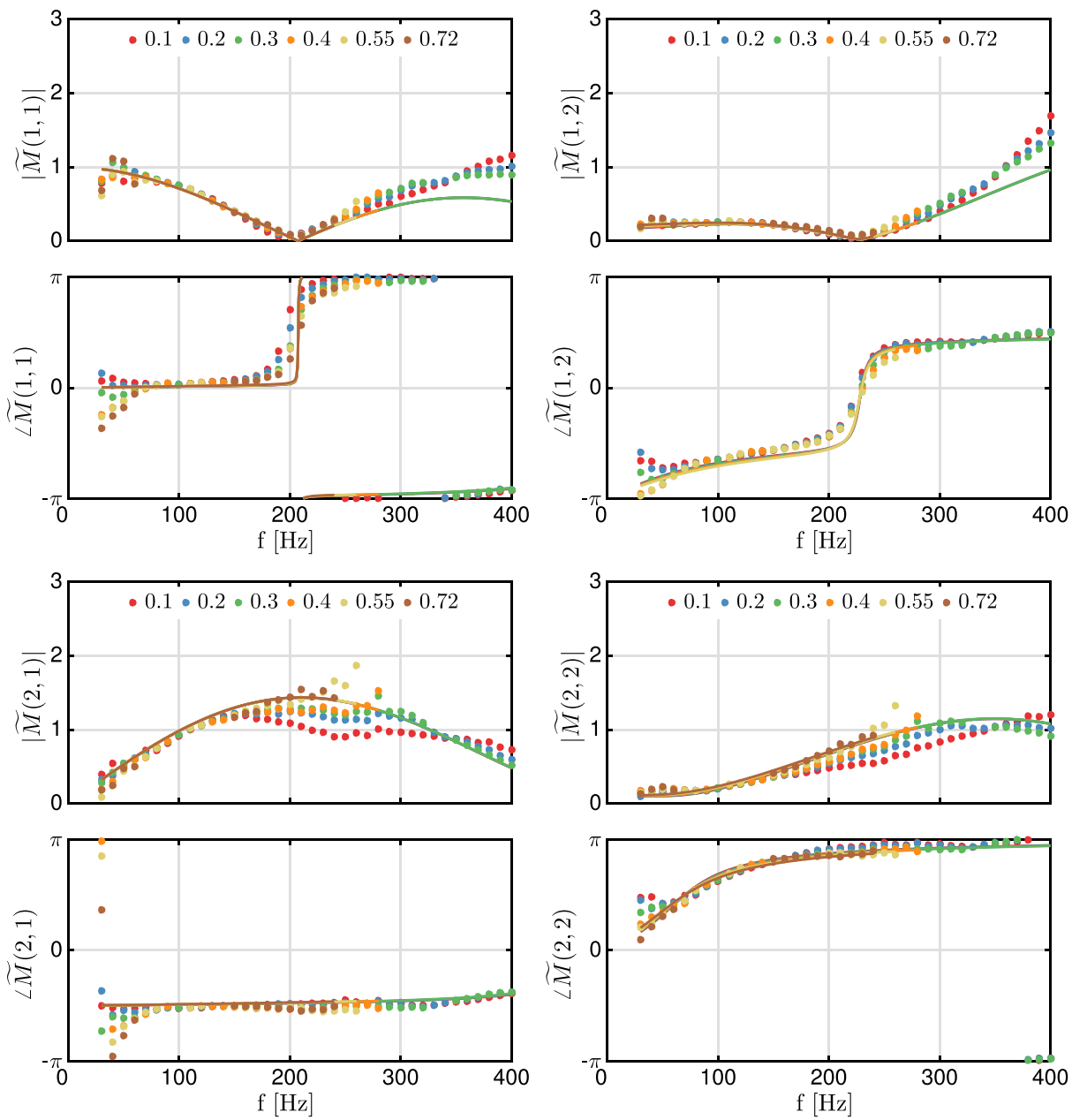

Fig. 5 Coefficients of the DATM representing the acoustic response of the system between the hot wire HW location in section (0) and the microphone ME" location in section (11) for cold flow operating conditions. (Top left): $\widetilde{M}(1,1)$ - (Top right): $\widetilde{M}(1,2)$ - (Bottom left): $\widetilde{M}(2,1)$ - (Bottom right): $\widetilde{M}(2,2)$. Measurements are performed for increasing forcing levels: $\left|u_{0}^{\prime}\right| / \bar{u}_{0}=0.10$ RMS (Red dots), $\left|u_{0}^{\prime}\right| / \bar{u}_{0}=0.20$ RMS (Blue dots), $\left|u_{0}^{\prime}\right| / \bar{u}_{0}=0.30 \mathrm{RMS}$ (Green dots), $\left|u_{0}^{\prime}\right| / \bar{u}_{0}=0.40$ RMS (Orange dots), $\left|u_{0}^{\prime}\right| / \bar{u}_{0}=0.55$ RMS (Yellow dots) and $\left|u_{0}^{\prime}\right| / \bar{u}_{0}=0.72$ RMS (Brown dots). The acoustic network model predictions are represented as solid lines for all forcing levels. For each plot, the top and bottom figures represent the modulus and phase of the DATM coefficient respectively 
The Dimensionless Acoustic Transfer Matrix $\tilde{M}$ representing the acoustic response of the central elements of the experimental setup located between section (0) and section (11) in Fig. 3-(Right) is then given by:

$$
\tilde{M}=\tilde{M}_{1011} \tilde{M}_{910} \tilde{M}_{89} \tilde{M}_{78} \tilde{M}_{67} \tilde{M}_{36} \tilde{M}_{23} \tilde{M}_{12} \tilde{M}_{01}
$$

\section{Results and Discussion}

\subsection{Cold flow operating conditions}

Figure 5 shows the modulus and phase of the four complex DATM coefficients $\tilde{M}(1,1)$, $\widetilde{M}(1,2), \widetilde{M}(2,1)$ and $\widetilde{M}(2,2)$ representing the acoustic response of the system between section (0) and section (11) in Fig. 3-(Right) and reconstructed from the experimental data for cold flow operating conditions. Measurements are performed for increasing forcing levels ranging from $\left|u_{0}^{\prime}\right| / \bar{u}_{0}=0.10$ to 0.72 RMS. These measurements are plotted as symbols in Fig. 5. The DATM coefficients predicted according to the acoustic network model shown in Fig. 4-(Top) are also plotted as solid lines in Fig. 5 for all forcing levels.

The modulus and phase of the measured DATM coefficients shown in Fig. 5 are more scattered in the low-frequency region. This is due to low frequency noise, which is not fully eliminated by the averaging procedure of the raw data because they were recorded over a limited number of forcing cycles. Morever, the two independent acoustic boundary conditions needed to extract the DATM coefficients are close at low frequencies, which also decreases the signal-to-noise ratio. Except in the low frequency region, the phase of the measured DATM coefficients $\widetilde{M}(1,1), \widetilde{M}(1,2), \widetilde{M}(2,1)$ and $\widetilde{M}(2,2)$ remains roughly independent of the forcing level. The moduli of $\widetilde{M}(1,1)$ and $\widetilde{M}(1,2)$ are also identical for all forcing levels. For $f<150 \mathrm{~Hz}$, the moduli of $\widetilde{M}(2,1)$ and $\widetilde{M}(2,2)$ are independent of the forcing level, but as the frequency becomes larger, an increasingly large gap appears
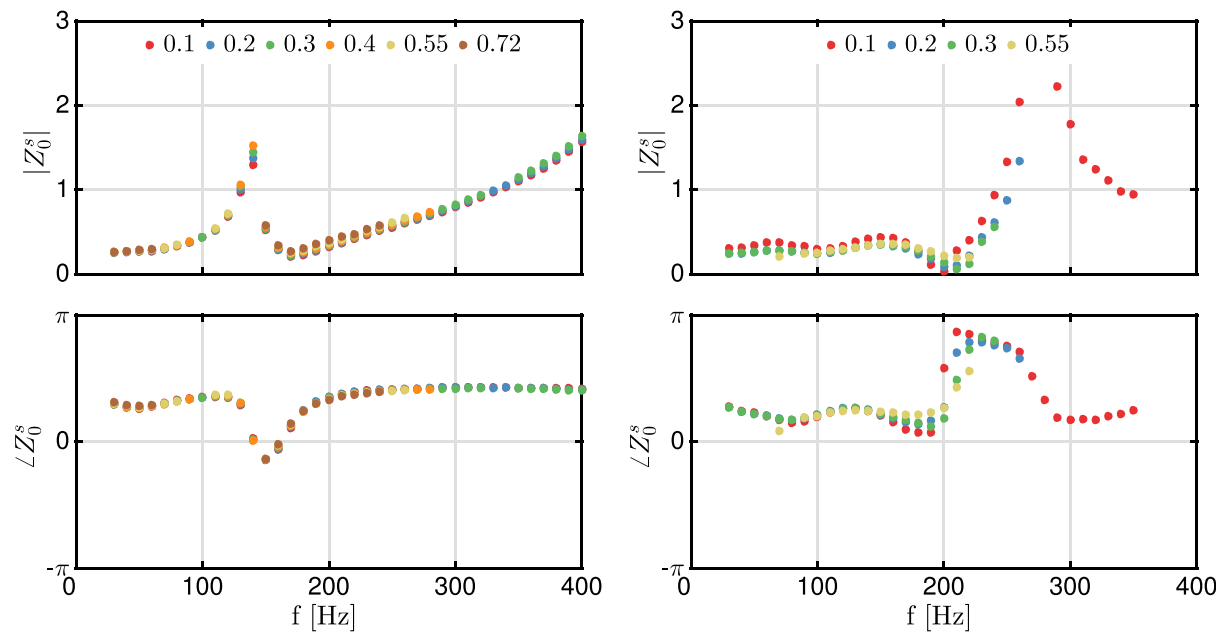

Fig. 6 Specific acoustic impedance $Z_{0}^{s}$ at the hot wire HW location as a function of the forcing frequency for cold (Left) and reactive (Right) operating conditions obtained using the first load. Results are shown for increasing forcing levels $\left|u_{0}^{\prime}\right| / \bar{u}_{0}$ measured by the hot wire probe HW 
between the data corresponding to the various forcing levels. The smaller the forcing level, the smaller the modulus of both coefficients $\widetilde{M}(2,1)$ and $\widetilde{M}(2,2)$.

This behavior cannot be reproduced by a linear acoustic network model, in which the effects of the forcing level are not considered. It is clear from Fig. 5 that the moduli of $\widetilde{M}(2,1)$ and $\widetilde{M}(2,2)$ linking the downstream acoustic velocity to the upstream acoustic pressure and acoustic velocity respectively appear to be nonlinear over a certain frequency range even in the absence of combustion. These nonlinearities may be either generated at the system boundaries or inside the system itself.

It is known that nonlinear acoustic losses at the system boundaries may perturb the measurements of the DATM as the forcing level increases [51, 52]. However, the specific acoustic impedances in section (0) and section (11) are independent of the forcing level, as shown in Figs. 6 and 7. The acoustic nonlinearities are thus generated between section (0), where the hot wire HW is located, and section (11), where the microphone ME" is located, as represented in Fig. 3-(Right).

It has long been recognized that a fraction of the acoustic energy is dissipated inside a burner submitted to sound waves [25, 53, 54]. This is generally modeled by a DATM expression with additional lump parameters, such as an effective length taking into account the inertia of the fluid and a pressure loss coefficient. An example of such a model is the $\zeta-l_{\text {eff }}$ model [25, 55-57]. These types of acoustic loss models yield good results for swirling injectors $[33,58]$, but they are linear. As a consequence, the predictions of the DATM coefficients according to these models do not depend on the forcing level and the nonlinearities observed in Fig. 5 cannot be explained by these models.

Based on earlier studies [44, 48], it is assumed that the main source of acoustic nonlinearities is the swirling vane, corresponding to the region between section (3) and section (6) in Fig. 3-(Right). The hot wire probe and microphone signals are then propagated just
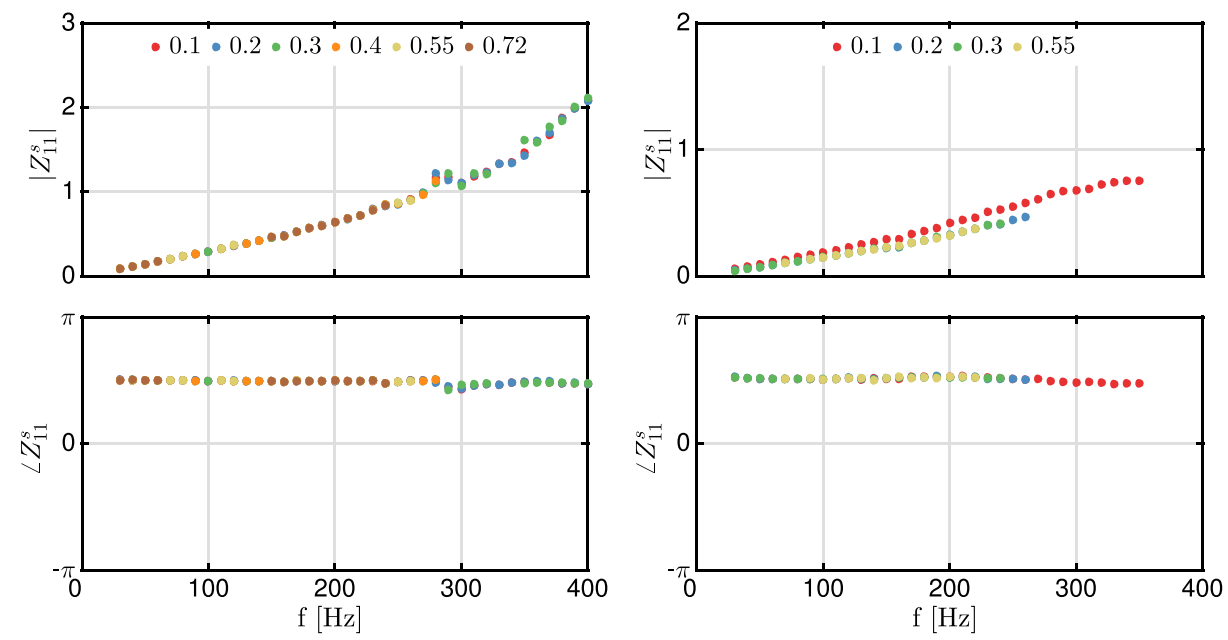

Fig. 7 Specific acoustic impedance $Z_{11}^{s}$ at the microphone ME" location as a function of the forcing frequency for cold (Left) and reactive (Right) operating conditions. The downstream boundary is a single exhaust tube with an open end, corresponding to the first load. Results are shown for increasing forcing levels $\left|u_{0}^{\prime}\right| / \bar{u}_{0}$ measured by the hot wire probe HW 
upstream and downstream the swirling vane, in section (3) and section (6). The DATM coefficients corresponding to the swirling vane alone are subsequently reconstructed and three DATM expressions modeling the acoustic response of the swirling vane are considered.

The first model corresponds to a compact area change given by Eq. 5 . The second model is based on Howe's model, given by Eq. 6, with a Rayleigh conductivity depending on the forcing frequency only. The effects of the finite thickness of the swirler channels are accounted for [45, 47, 49]. Finally, the third model is a nonlinear extension of Howe's model, where the Rayleigh conductivity depends on both the forcing frequency and amplitude of the acoustic velocity inside the swirler channels. In this model, the convection speed of the vortical structures that are periodically shed away from the perforation rim is not a constant as in Howe's model [45] but depends on the mean and acoustic velocity inside the swirler channels $u_{c}=\bar{u}_{4}+C u_{4}^{\prime}$ where $C=1 / 3$ based on earlier studies [44, 48]. The predictions according to these three models differ for coefficient $\widetilde{M}_{36}(1,2)$, linking the downstream acoustic pressure to the upstream acoustic velocity, but not for coefficients $\widetilde{M}_{36}(1,1), \widetilde{M}_{36}(2,1)$ and $\widetilde{M}_{36}(2,2)$. As a consequence, the analytical and experimental results are plotted in Fig. 8 for coefficient $\widetilde{M}_{36}(1,2)$ only. Two limit cases are considered : Fig. 8-(Left) corresponds to a small forcing level $\left|u_{0}^{\prime}\right| / \bar{u}_{0}=0.10$ RMS while Fig. 8-(Right) corresponds to a large forcing level $\left|u_{0}^{\prime}\right| / \bar{u}_{0}=0.72 \mathrm{RMS}$.

The analytical model corresponding to a compact area change predicts that $\tilde{M}_{36}(1,2)=$ 0 for all forcing frequencies and all forcing levels, which is in contradiction with measurements, as shown in Fig. 8. This observation corroborates the fact that damping has to be considered when modeling the acoustic response of the swirling vane. Both the linear and nonlinear expressions based on Howe's model allow for acoustic damping. As expected, the predictions of these linear and nonlinear models are similar for a limited forcing level, as
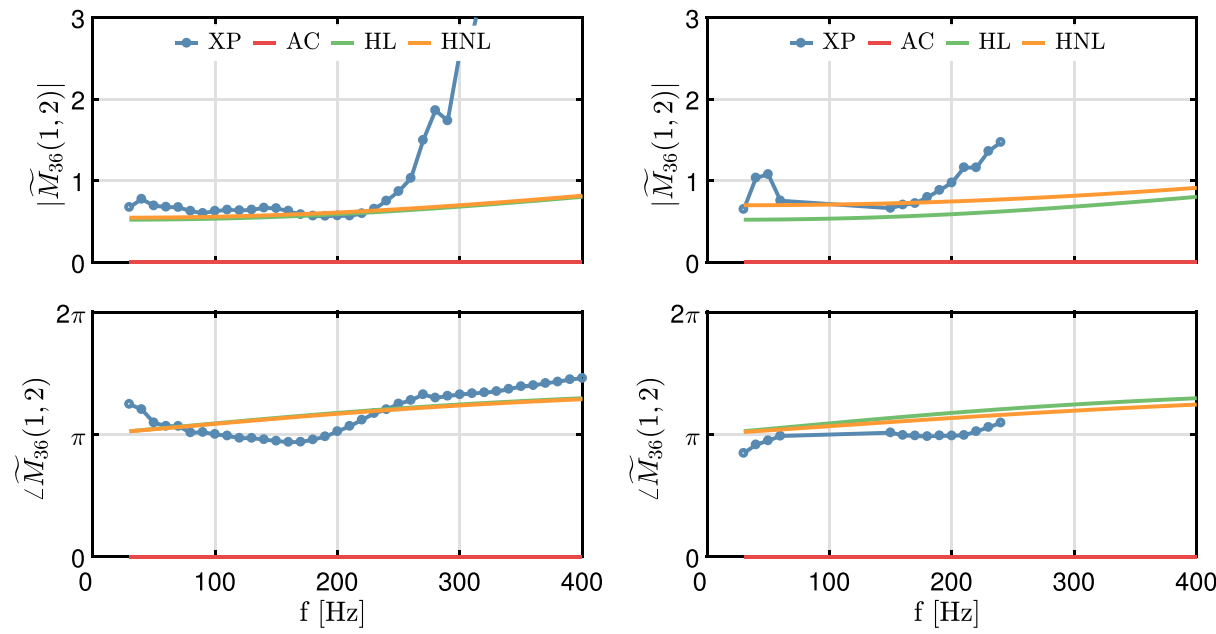

Fig. 8 Coefficient $\widetilde{M}_{36}(1,2)$ of the DATM representing the acoustic response of the swirler between section (3) and section (6) for cold flow operating conditions and for two different forcing levels. (Left): $\left|u_{0}^{\prime}\right| / \bar{u}_{0}=0.10 \mathrm{RMS}$ - (Right): $\left|u_{0}^{\prime}\right| / \bar{u}_{0}=0.72 \mathrm{RMS}$. (Blue circles): Measurements (XP) - (Red line): Predictions with a compact area change model (AC) - (Green line): Predictions according to Howe's model with a linear Rayleigh conductivity (HL) - (Orange line): Predictions according to Howe's model with a nonlinear Rayleigh conductivity (HNL). For each plot, the top and bottom figures represent the modulus and phase of the DATM coefficient respectively 
shown in Fig. 8-(Left). The predicted modulus of coefficient $\widetilde{M}_{36}(1,2)$ is in good agreement with measurements for forcing frequencies $f<220 \mathrm{~Hz}$. Furthermore, the predicted phase of coefficient $\widetilde{M}_{36}(1,2)$ is adequate for all the forcing frequencies investigated.

Differences between the predictions according to the linear and nonlinear expressions based on Howe's model arise when a sizeable forcing level is considered, as represented in Fig. 8-(Right). At all forcing frequencies, the nonlinear model predicts a larger modulus and a smaller phase for $\widetilde{M}_{36}(1,2)$ compared to the linear model. Figure 8-(Right) clearly shows that the nonlinear model is in better agreement with measurements compared to the linear model.

As a consequence, the acoustic response of the swirling vane is modeled in this work with a nonlinear extension of Howe's model given by Eq. 6, where the Rayleigh conductivity depends on both the forcing frequency and amplitude of the acoustic waves inside the swirling vane. This model takes into account the acoustic energy dissipation due to the interaction of sound waves with large vortical structures $[45,46]$. The swirler's finite thickness is also accounted for $[44,50]$. For cold flow operating conditions, this analytical model constitutes the only source of nonlinearity in the acoustic network model represented in Fig. 4-(Top) since the amplitude of the acoustic velocity does not appear in any other DATM model.

The analytical predictions according to the acoustic network model represented in Fig. 4(Top), which accounts for the nonlinear acoustic damping generated by the swirling vane, are represented as solid lines in Fig. 5 for increasing forcing levels. Overall, the agreement between the analytical predictions and the modulus and phase of the measured DATM coefficients is excellent, except in the high-frequency range where the moduli of $\widetilde{M}(1,1)$ and $\tilde{M}(1,2)$ are slightly underpredicted and the moduli of $\tilde{M}(2,1)$ and $\tilde{M}(2,2)$ are slightly overpredicted. On the other hand, the phase of all DATM coefficients are well predicted by the analytical model for all frequencies and all forcing levels investigated.

As detailed earlier, the acoustic network model represented in Fig. 4-(Top) accounts for the nonlinear acoustic losses at the swirling vane. Nevertheless, it is clear from Fig. 5 that the impact of the forcing level on the moduli of $\widetilde{M}(2,1)$ and $\widetilde{M}(2,2)$ is not correctly predicted by this network model. For instance, the modulus of $\tilde{M}(2,1)$ measured at a forcing frequency $f=240 \mathrm{~Hz}$ and at a forcing level $\left|u_{0}^{\prime}\right| / \bar{u}_{0}=0.10 \mathrm{RMS}$ is $40 \%$ smaller than the same modulus measured at the same frequency but at a forcing level $\left|u_{0}^{\prime}\right| / \bar{u}_{0}=0.72 \mathrm{RMS}$. According to the acoustic network model represented in Fig. 4-(Top), this gap is expected to be smaller than $1 \%$ at this forcing frequency.

It is thus concluded that for cold flow operating conditions, either the effects of the nonlinear acoustic losses at the swirling vane are highly underestimated by the acoustic network model or another source of nonlinearity was not taken into account. For instance, the acoustic waves may also be damped at the injector rim, corresponding to the region between section (7) and section (8) in Fig. 4-(Top), where vortical structures are shed periodically and may also interact with sound waves. An additional modeling effort is thus needed to correctly predict the nonlinear acoustic losses inside swirling injectors exhausting gases in a combustion chamber. Moreover, the experiments conducted in this work for cold flow operating conditions show that nonlinear acoustic losses need to be considered when modeling the DATM coefficients of the system between section (0) and section (11) as the forcing level is increased.

It is now worth investigating the acoustic response of the combustor for reactive operating conditions. In this case, the flame constitutes another source of acoustic nonlinearity which also alters the acoustic response of the system. 


\subsection{Reactive operating conditions}

Measurements and analytical predictions of the modulus and phase of the four DATM coefficients $\widetilde{M}(1,1), \widetilde{M}(1,2), \widetilde{M}(2,1)$ and $\widetilde{M}(2,2)$ representing the acoustic response of the system between the hot wire HW location in section (0) and the microphone ME" location in section (11) are reported in Fig. 9 for reactive operating conditions and for increasing acoustic forcing levels ranging from $\left|u_{0}^{\prime}\right| / \bar{u}_{0}=0.10 \mathrm{RMS}$ to $0.55 \mathrm{RMS}$.

Once again, a higher variability of the DATM coefficients reconstructed from measurements is observed for low forcing frequencies because of the limited number of
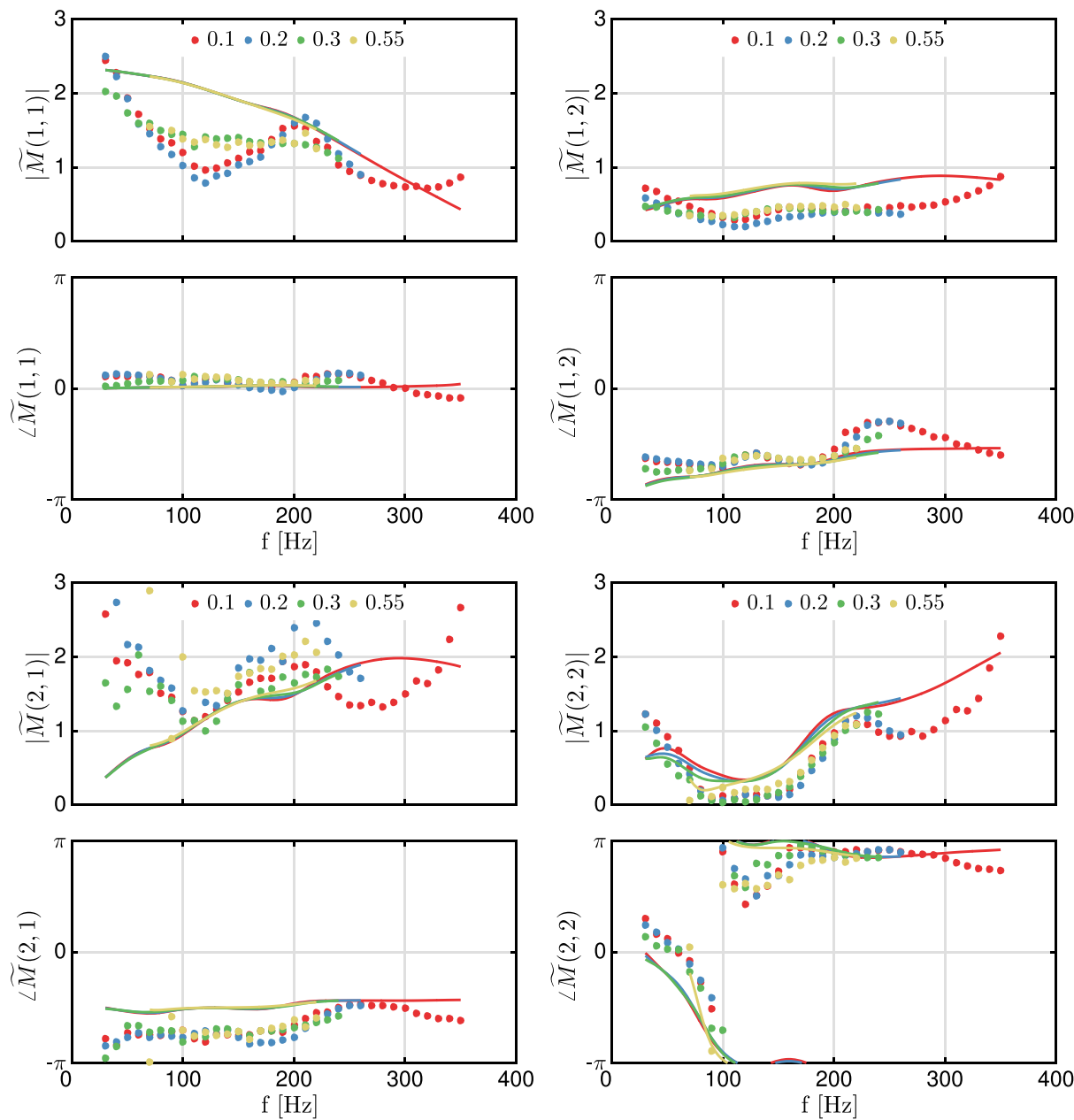

Fig. 9 Coefficients of the DATM representing the acoustic response of the system between the hot wire HW location in section (0) and the microphone ME" location in section (11) for reactive operating conditions. (Top left): $\widetilde{M}(1,1)$ - (Top right): $\widetilde{M}(1,2)$ - (Bottom left): $\widetilde{M}(2,1)$ - (Bottom right): $\widetilde{M}(2,2)$. Measurements are performed for increasing forcing levels: $\left|u_{0}^{\prime}\right| / \bar{u}_{0}=0.10 \mathrm{RMS}$ (Red dots), $\left|u_{0}^{\prime}\right| / \bar{u}_{0}=0.20 \mathrm{RMS}$ (Blue dots), $\left|u_{0}^{\prime}\right| / \bar{u}_{0}=0.30$ RMS (Green dots) and $\left|u_{0}^{\prime}\right| / \bar{u}_{0}=0.55$ RMS (Yellow dots). Acoustic network model predictions are represented as solid lines for all forcing levels. For each plot, the top and bottom figures represent the modulus and phase of the DATM coefficient respectively 
forcing cycles in the recorded signals and because the two independent acoustic boundary conditions become close at low frequencies. Moreover, the flame generates broadband combustion noise thus affecting the overall signal-to-noise ratio in Fig. 9 compared to the results obtained for cold flow conditions presented in Fig. 5.

Figure 9 highlights the fact that all four measured DATM coefficients depend on the forcing level $\left|u_{0}^{\prime}\right| / \bar{u}_{0}$ to some extent over a certain frequency range. For all forcing frequencies investigated, the moduli of $\tilde{M}(1,1)$ and $\widetilde{M}(2,1)$ are strongly affected when the forcing level is increased while the moduli of $\widetilde{M}(1,2)$ and $\widetilde{M}(2,2)$ are only slightly affected by changes of the forcing level. Moreover, the phases of all measured DATM coefficients only marginally depend on the forcing level.

The impact of the forcing level on the measured DATM coefficients appears to be more important for reactive operating conditions, shown in Fig. 9, than for cold operating conditions, shown in Fig. 5. An initial conjecture would be to relate these observations to the nonlinear flame response when submitted to high-amplitude acoustic forcing.

The analytical predictions of the DATM coefficients for reactive operating conditions according to the acoustic network model represented in Fig. 4-(Bottom) are also determined for all forcing levels investigated. These predictions are plotted in Fig. 9 as solid lines. The nonlinear flame response is accounted for through the use of the Flame Describing Function (FDF), determined by optical means and represented in Fig. 10-(Right). This FDF is obtained by forcing the flame with the loudspeaker while recording the velocity signal $\bar{u}_{0}+u_{0}^{\prime}$ at the hot wire location, corresponding to section (0) in Fig. 3-(Right), and simultaneously recording the light emission from the combustion region with a photomultiplier equipped with an $\mathrm{OH}^{*}$ filter. The acoustic velocity $u_{7}^{\prime}$ at the top of the injector in section (7) is then deduced from the hot wire signal and a propagation model $[44,50]$.

Overall, the agreement between the acoustic network model predictions and the corresponding measurements of $\widetilde{M}(1,2)$ and $\widetilde{M}(2,2)$ is satisfactory. On the other hand, the modulus of $\widetilde{M}(1,1)$ and the modulus and phase of $\widetilde{M}(2,1)$ are only partially captured.

The predictions of coefficients $\widetilde{M}(1,1), \widetilde{M}(1,2)$ and $\widetilde{M}(2,1)$ according to the acoustic network model shown in Fig. 4-(Bottom) are found to be almost insensitive to the acoustic forcing level, as shown in Fig. 9. For instance, even though the general trend of the modulus of $\widetilde{M}(2,1)$ is reproduced by the acoustic network model, the impact of the forcing level on the measured coefficient is much larger than expected from the acoustic network analysis fed with the FDF. On the other hand, the predictions for coefficient $\widetilde{M}(2,2)$ vary significantly when the forcing level is modified but these variations do not fully represent the experimental observations, as shown in Fig. 9.

It is worth emphasizing that the FDF appears in the velocity/velocity component $\tilde{M}(2,2)$ of the DATM representing the acoustic response of the flame, given by Eq. 3. However, the DATM linking the acoustic pressure $p_{11}^{\prime}$ and acoustic velocity $u_{11}^{\prime}$ at the microphone ME" location to the acoustic pressure $p_{0}^{\prime}$ and acoustic velocity $u_{0}^{\prime}$ at the hot wire location is not compact due to the large distance separating these locations. As a consequence, the contribution of the DATM representing the compact flame spreads to the other DATM coefficients representing the entire burner/flame response to sound waves because of the matrix product appearing in Eq. 7. Hence, the nonlinearities due to the flame response may be present in all four DATM coefficients represented in Fig. 9.

In addition to the nonlinearities generated by the flame response, the coupling between vortical structures and sound waves described earlier for cold flow operating conditions using a nonlinear extension of Howe's model still constitutes a source of acoustic nonlinearity for reactive operating conditions. In the end, the nonlinearities observed in the acoustic network model predictions represented in Fig. 9 originate from both phenomena. 
The last step is to reconstruct the FDF obtained with optical measurements from the acoustic network model and the hot wire HW and microphones MHW, ME, ME' and ME" signals. In most industrial burners, measuring the flame heat release rate is challenging, as explained in the introduction. Since the Flame Describing Function is an important tool that can be used to perform a thermoacoustic stability analysis, it is worth examining whether the FDF can be reconstructed from acoustic measurements only.

The DATM describing the flame response to harmonic sound waves is extracted using the following procedure. The DATM denoted by $\tilde{M}$ which describes the acoustic response of the combustor/flame system located between section (0) and section (11) is first extracted from the hot wire and microphone measurements. Then, the different DATM denoted by $\widetilde{M}_{i j}$ corresponding to the acoustic response of the single acoustic elements are all modeled using analytical DATM, except for $\widetilde{M}_{78}$ corresponding to the flame element. This latest DATM is deduced using Eq. 7 rearranged in the following way :

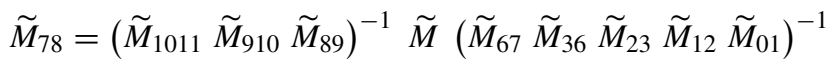

The resulting DATM denoted by $\tilde{M}_{78}$ describes the acoustic response of the system between section (7) and section (8), where the flame is located. This data-driven reconstruction of $\widetilde{M}_{78}$ is then compared with the analytical model given by Eq. 3 and the Flame Describing Function is subsequently deduced from the velocity/velocity component of the reconstructed DATM coefficient $\widetilde{M}_{78}$. This procedure can be used to determine the FDF solely from acoustic pressure and acoustic velocity measurements at any distance from the flame when used in association with an acoustic network model of the reactive system.
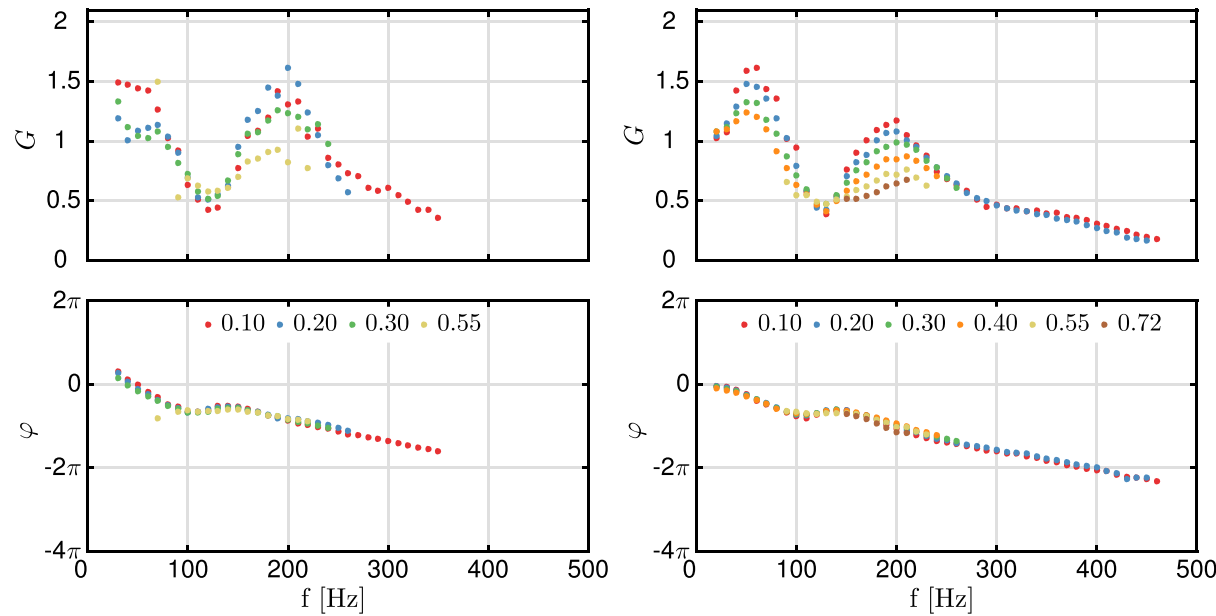

Fig. 10 Gain (Top) and phase (Bottom) of the Flame Describing Function (FDF) as a function of the forcing frequency for increasing forcing levels $\left|u_{0}^{\prime}\right| / \bar{u}_{0}=0.10$ RMS (Red dots), $\left|u_{0}^{\prime}\right| / \bar{u}_{0}=0.20$ RMS (Blue dots), $\left|u_{0}^{\prime}\right| / \bar{u}_{0}=0.30 \mathrm{RMS}$ (Green dots), $\left|u_{0}^{\prime}\right| / \bar{u}_{0}=0.40 \mathrm{RMS}$ (Orange dots), $\left|u_{0}^{\prime}\right| / \bar{u}_{0}=0.55$ RMS (Yellow dots) and $\left|u_{0}^{\prime}\right| / \bar{u}_{0}=0.72$ RMS (Brown dots). (Left): Reconstruction from the acoustic network model and the acoustic pressure and acoustic velocity measurements in section (0) and section (11). (Right): Reconstruction from the acoustic velocity measurement in section $(0)$ and the $\mathrm{OH}^{*}$ chemiluminescence signal 
Figure 10-(Left) represents this data-driven reconstruction while Fig. 10-(Right) represents the corresponding FDF determined optically using a photomultiplier with an $\mathrm{OH}^{*}$ filter. The FDF obtained from optical measurements is now described. First, the FDF gain increases with increasing frequencies before a sudden drop, followed by a second increase and then a smooth decrease at high frequencies. This type of frequency response is typical of premixed swirling flames anchored on a central bluff body [59, 60]. The overall flame response drops as the forcing level $\left|u_{0}^{\prime}\right| / \bar{u}_{0}$ increases except in the low-gain valley, for forcing frequencies between $100 \mathrm{~Hz}$ and $150 \mathrm{~Hz}$. In this region, the FDF remains roughly independent of the forcing level whereas at lower and higher frequencies, the FDF gain is impacted by the forcing level set at the hot wire location.

The overall shape of the reconstructed FDF obtained from acoustic measurements, represented in Fig. 10-(Left), is in good agreement with the FDF obtained with the photomultiplier, represented in Fig. 10-(Right). The FDF gain in Fig. 10-(Right) starts at unity at low frequency, as expected from theory [61]. On the other hand, the FDF gain at low frequencies predicted by the data-driven DATM reconstructions are overestimated, as shown in Fig. 10-(Left). Nevertheless, the evolution of the acoustically reconstructed FDF gain with the forcing level is fairly well captured except for forcing frequencies $f<50 \mathrm{~Hz}$ and $150 \mathrm{~Hz}<f<250 \mathrm{~Hz}$ where it is overestimated. On the other hand, the FDF phase lag is perfectly captured for forcing frequencies $f>50 \mathrm{~Hz}$. At lower frequencies, the data-driven FDF reconstruction is less accurate because of the limited number of forcing cycles in the recorded signals. Both the acoustically reconstructed and optically measured FDF phase lag are independent of the forcing level $[59,60]$ and are in excellent agreement with each other.

It is thus concluded that the FDF phase lag of a premixed confined turbulent swirling flame can be accurately captured from an acoustic network model used in association with acoustic measurements at the system inlet and outlet. On the other hand, the data-driven reconstruction of the FDF gain is more difficult and even though the overall evolution of the FDF gain with the forcing frequency and forcing level is fairly well predicted, some deviations may be observed between the optical and purely acoustic techniques. These deviations may have several origins:

- The acoustic reconstruction of the FDF is more sensitive to low frequency noise than the optical technique. At low forcing frequencies, the specific acoustic impedances of the two configurations of the burner that are needed to extract the DATM coefficients tend to be relatively close. As a consequence, the quality of the acoustic reconstruction decreases at low frequencies. Moreover, combustion noise generated by the turbulent flame also decreases the signal-to-noise ratio when determining the DATM coefficients for reactive operating conditions. On the other hand, combustion noise has a limited impact when determining the FDF using the optical technique.

- The acoustic reconstruction of the FDF relies on the quality and accuracy of the models used to describe the acoustic response of all the elements present inside the combustor between section (0) and section (11). However, it was shown that the acoustic response of the burner for cold flow operating conditions is not fully reproduced by the acoustic network model. As a consequence, the acoustic reconstruction of the FDF is altered because the models are not accurate enough.

- The optical technique used to determine the FDF relies on the hypothesis that the $\mathrm{OH}^{*}$ chemiluminescence signal is proportional to the flame heat release rate. Even though this relation is well-established for perfectly premixed lean hydrocarbon flames, the accuracy of this approximation remains difficult to quantify. 


\section{Conclusion}

The impact of the forcing level $\left|u_{0}^{\prime}\right| / \bar{u}_{0}$ on the complex Dimensionless Acoustic Transfer Matrix (DATM) coefficients describing the acoustic response of a confined turbulent swirling combustor was determined for cold and reactive operating conditions. The specific acoustic impedances at the system inlet and outlet were also measured for all operating conditions and all forcing frequencies and were found to be independent of the forcing level. The Flame Describing Function (FDF) of the turbulent swirling flame was also measured with a photomultiplier mounted with an $\mathrm{OH}^{*}$ filter for the same forcing levels and forcing frequencies.

The acoustic response of the system comprised between the hot wire HW location and the uppermost microphone ME" location was first measured for cold flow operating conditions. The phases of the DATM coefficients representing the whole system dynamics were found to be mostly independent of the forcing level $\left|u_{0}^{\prime}\right| / \bar{u}_{0}$. Likewise, the moduli of the DATM coefficients linking the downstream pressure fluctuations to the upsteam pressure and velocity fluctuations were found to be the same for all forcing levels. On the other hand, the moduli of the DATM coefficients linking the downstream velocity fluctuations to the upstream pressure and velocity fluctuations were found to be strongly impacted by the forcing level $\left|u_{0}^{\prime}\right| / \bar{u}_{0}$ for a range of forcing frequencies.

For reactive operating conditions, the phases of the DATM coefficients were still found to be mostly independent of the forcing level for all forcing frequencies. Moreover, the moduli of the DATM coefficients linking the downstream pressure and velocity fluctuations to the upsteam velocity fluctuations were found to weakly depend on the forcing levels while the moduli of the DATM coefficients linking the downstream pressure and velocity fluctuations to the upsteam pressure fluctuations were found to strongly depend on the forcing level $\left|u_{0}^{\prime}\right| / \bar{u}_{0}$ over a certain frequency range.

Two acoustic network models describing the response of the system between the hot wire HW location and the uppermost microphone ME" location were designed for cold and reactive operating conditions. Two sources of acoustic nonlinearities were considered in the network models. First, the acoustic nonlinearities generated at the rim of the swirling vane channels because of the coupling between sound waves and vortical structures convected by the mean flow were included in the cold and reactive acoustic network models. The corresponding model, based on a nonlinear extension of Howe's model, was shown to better capture the acoustic response of the swirling vane at low frequencies compared to Howe's model. Furthermore, the flame nonlinearities were also accounted for in the reactive case through the use of the FDF.

For cold flow operating conditions, the acoustic network model was found to be in good agreement with measurements. The phases of the reconstruced DATM coefficients were found to be independent of the forcing level, which corresponds to the experimental observations. Moreover, the agreement between the phases of the measured and predicted DATM coefficients was shown to be excellent. The moduli of the pressure/pressure and pressure/velocity DATM coefficients were also well predicted by the acoustic network model. On the other hand, the moduli of the velocity/pressure and velocity/velocity DATM coefficients were still found to be fairly well predicted but the impact of the forcing level was not correctly reproduced by the DATM reconstruction.

For reactive operating conditions, the general trends of the four DATM coefficients were still shown to be roughly reproduced by the acoustic model but the agreement between the measured DATM coefficients and the corresponding reconstructions from the acoustic 
network model were found to worsen compared to cold flow conditions. The impact of the forcing level on the predicted DATM coefficients was not well captured.

Finally, the FDF was reconstructed from the DATM measurements and the acoustic network model developed for reactive operating conditions. The data-driven reconstruction of the FDF was then compared to the FDF obtained with an optical technique. The agreement between the measured and reconstructed FDF was found to be good even though the FDF gain was largely overestimated for certain frequency ranges. On the other hand, the FDF phase lag was shown to be well captured and the variations of both the FDF gain and phase lag with the forcing level were found to be satisfactorily explained.

These experiments confirm that some of the DATM coefficients representing the acoustic response of the burner/flame system highly depend on the forcing level for both cold and reactive operating conditions. The nonlinear acoustic losses at the swirler holes coupled with the flame nonlinearities (for reactive conditions) were modeled in the acoustic network models, but these elements did not allow to entirely reproduce the impact of the forcing level on these DATM coefficients. This study emphasizes the need for new analytical models predicting the nonlinear acoustic losses inside turbulent swirling injectors.

This study also highlights the difficulties when extracting the Flame Describing Function from purely acoustic measurements. This method requires accurate Dimensionless Acoustic Transfer Matrix models for all the acoustic elements but it also requires precise measurements of the total DATM representing the response of the whole burner/flame system.

Funding This work is supported by Agence Nationale de la Recherche, NOISEDYN project (ANR-14CE35-0025-01). This project has also received funding from the European Union Horizon 2020 research and innovation programme under the Marie Sklodowska-Curie grant agreement No 643134.

\section{Compliance with Ethical Standards}

Conflict of interests The authors declare that they have no conflict of interest.

\section{References}

1. Keller, J.J.: AIAA J. 33(12), 2280 (1995)

2. Dowling, A.P., Stow, S.R.: J. Propul. Power 19(5), 751 (2003)

3. Sattelmayer, T., Polifke, W.: Combust. Sci. Technol. 175(3), 453 (2003)

4. Nicoud, F., Benoit, L., Sensiau, C., Poinsot, T.: AIAA J. 45(2), 426 (2007)

5. Camporeale, S.M., Fortunato, B., Campa, G.: J. Eng. Gas Turbines Power 133(1), 011506 (2011)

6. Candel, S.: Combust, Proc. Inst. 29, 1 (2002)

7. Dowling, A.P.: J. Fluid Mech. 346, 271 (1997)

8. Noiray, N., Durox, D., Schuller, T., Candel, S.: J. Fluid Mech. 615, 139 (2008)

9. Palies, P., Durox, D., Schuller, T., Candel, S.: Combust. Flame 158(10), 1980 (2011)

10. Ćosić, B., Moeck, J.P., Paschereit, C.O.: Combust. Sci. Technol. 186, 713 (2014)

11. Laera, D., Schuller, T., Prieur, K., Durox, D., Camporeale, S.M.: Combust. Flame 184, 136 (2017)

12. Silva, C.F., Nicoud, F., Schuller, T., Durox, D., Candel, S.: Combust. Flame 160(9), 1743 (2013)

13. Schuller, T., Durox, D., Candel, S.: Combust. Flame 134, 21 (2003)

14. Preetham, S.H., Hemchandra, S., Lieuwen, T.: J. Propul. Power 24(6), 1390 (2008)

15. Krediet, H.J., Beck, C.H., Krebs, W., Schimek, S., Paschereit, C.O.: Combust. Sci. Technol. 184(7-8), 888 (2012)

16. Han, X., Li, J., Morgans, A.S.: Combust. Flame 162(10), 3632 (2015)

17. Poinsot, T.: Combust, Proc. Inst. 36(1), 1 (2017)

18. Han, X., Morgans, A.S.: Combust. Flame 162(5), 1778 (2015)

19. Li, J., Xia, Y., Morgans, A.S., Han, X.: Combust. Flame 185, 28 (2017)

20. Noiray, N., Schuermans, B.: Proc. Roy. Soc. A 469(2151), 20120535 (2013) 
21. Ghirardo, G., Ćosić, B., Juniper, M.P., Moeck, J.P.: Nonlinear Dyn. 82(1-2), 9 (2015)

22. Ćosić, B., Terhaar, S., Moeck, J.P., Paschereit, C.O.: Combust. Flame 162(4), 1046 (2015)

23. Giuliani, F., Lang, A., Johannes Gradl, K., Siebenhofer, P., Fritzer, J.: J. Eng. Gas Turbines Power 134, 021602 (2012)

24. Hurle, I.R., Price, R.B., Sugden, T.M., Thomas, A.: Proc. R. Soc. A 303, 409 (1968)

25. Paschereit, C.O., Polifke, W.: In: Proceedings of the ASME Turbo Expo 1998, pp. 1-10 (1998)

26. Paschereit, C.O., Schuermans, B., Polifke, W., Mattson, O.: J. Eng. Gas Turbines Power 124, 239 (2002)

27. Fischer, A., Hirsch, C., Sattelmayer, T.: J. Sound Vib. 298(1-2), 73 (2006)

28. Alemela, P., Fanca, D., Ettner, F., Hirsch, C., Sattelmayer, S.: In: Proceedings of the ASME Turbo Expo 2008, pp. 1-9 (2008)

29. Truffin, K., Poinsot, T.: Combust. Flame 142(4), 388 (2005)

30. Abom, M.: J. Sound Vib. 155(1), 185 (1992)

31. Munjal, M.L.: Acoustics of ducts and mufflers. Wiley, New York (1987)

32. Schuermans, B., Polifke, W., Paschereit, C.O., van der Linden, J.H.: In: Proceedings of the ASME Turbo Expo 2000 (2000)

33. Polifke, W., Poncet, A., Paschereit, C., Döbbeling, K.: J. Sound Vib. 245, 483 (2001)

34. Gentemann, A., Polifke, W.: In: Proceedings of the ASME Turbo Expo, p. 2007 (2007)

35. Duchaine, F., Selle, L., Poinsot, T.: Combust. Flame 158(12), 2384 (2011)

36. Tay Wo Chong, L., Komarek, T., Kaess, R., Föller, S., Polifke, W.: In: Proceedings of the ASME Turbo Expo 2010 (2010)

37. Tay-Wo-Chong, L., Bomberg, S., Ulhaq, A., Polifke, W.: J. Eng. Gas Turbines Power 134(2), 021502 (2012)

38. Lieuwen, T.C.: Unsteady combustor physics. Cambridge University Press, Cambridge (2005)

39. Durox, D., Schuller, T., Noiray, N., Candel, S.: Proc. Combust. Inst. 32, 1391 (2009)

40. Chung, J.Y., Blaser, D.A., Acoust, J.: Soc. Am. 68, 907 (1980)

41. Scarpato, A., Tran, N., Ducruix, S., Schuller, T.: J. Sound Vib. 331, 276 (2012)

42. Guedra, M., Penelet, G., Lotton, P., Dalmont, J., Acoust, J.: Soc. Am. 130(7), 145 (2011)

43. Poinsot, T., Veynante, D.: Theoretical and numerical combustion (2005)

44. Gaudron, R., Gatti, M., Mirat, C., Schuller, T.: J. Eng. Gas Turbines Power. 141(5), 051016 (2019)

45. Howe, M.S.: Lond, Proc. R. Soc. A 366, 205 (1979)

46. Howe, M.S.: Acoustics of fluid-structure interactions. Cambridge University Press, Cambridge (1998)

47. Jing, X., Sun, X.: AIAA J. 38(9), 1573-1578 (2000)

48. Scarpato, A.: Linear and nonlinear analysis of the acoustic response of perforated plates traversed by a bias flow. Ph.D. thesis, Ecole Centrale Paris (2014)

49. Luong, T., Howe, M.S., McGowan, R.S.: J. Fluids Struct. 21(8), 769 (2005)

50. Gaudron, R.: Acoustic response of premixed flames submitted to harmonic sound waves. Ph.D. thesis, Université Paris-Saclay (2018)

51. Heckl, M.: Acoustica 72, 63 (1990)

52. Schuller, T., Tran, N., Noiray, N., Durox, D., Ducruix, S., Candel, S.: In: Proceedings of the ASME Turbo Expo 2009, pp. GT2009-59390 (2009)

53. Kruger, U., Hüren, J., Hoffmann, S., Krebs, W., Flohr, P., Bohn, D.: J. Eng. Gas Turbines Power 123(3), 557 (2001)

54. Su, J., Garmory, A., Carrotte, J.: In: Proceedings of the ASME Turbo Expo 2015 (2015)

55. Hirschberg, A.: Introduction to aero-acoustics of internal flow. Tech. rep (2001)

56. Gentemann, A., Fischer, A., Evesque, S., Polifke, W.: In: 9th AIAA/CEAS aeroacoustics conference and exhibit, May 12-14, 2003, Hilton Head, South Carolina, pp. 1-11 (2003)

57. Polifke, W., Fischer, A., Sattelmayer, T.: J. Eng. Gas Turbines Power 125, 20 (2003)

58. Ni, F., Miguel-Brebion, M., Nicoud, F., Poinsot, T.: AIAA J. 55(4), 1205 (2017)

59. Palies, P., Durox, D., Schuller, T., Candel, S.: Combust. Flame 157, 1698 (2010)

60. Gatti, M., Gaudron, R., Mirat, C., Schuller, T.: In: Proceedings of the ASME Turbo Expo 2017, pp. 1-11 (2017)

61. Polifke, W., Lawn, C.J.: Combust. Flame 151(3), 437 (2007) 


\section{Affiliations}

R. Gaudron ${ }^{1}$ (D) $\cdot$ M. Gatti ${ }^{1} \cdot$ C. Mirat ${ }^{1} \cdot$ T. Schuller $^{1,2}$

1 Laboratoire EM2C, CNRS, CentraleSupélec, Université Paris-Saclay, 3 rue Joliot Curie, 91192, Gif-sur-Yvette cedex, France

2 Institut de Mécanique des Fluides de Toulouse, IMFT, Université de Toulouse, CNRS, Toulouse, France 